LÓPEZ GONZÁLEZ, Clemente

Universidad Francisco de Vitoria

@ c.lopez@ufv.com

RUIZ RODRÍGUEZ, José Ignacio

Universidad de Alcalá

@jignacio.ruiz@alcala.es

\title{
Identidad, violencia y religión en la época de las Reformas
}

\section{Identity, violence and religion at the time of the Reforms}

Para René Girard, después de la Reforma, cuando el fervor religioso declinó, las guerras de religión aumentaron en Europa.

PALABRAS CLAVE: Girard, Reforma, Europa, religión.

For Regé Girard, after the Reformation, when religious fervor declined, religious wars increased in Europe.

KEY WORDS: Girard, Reformation, Europe, religious.

Para René Girard, después de la Reforma, cuando el fervor religioso declinó, las guerras de religión aumentaron en Europa (Girard, 2016, p. 11). Este planteamiento, por ser tan general y al mismo tiempo tan sugerente, invita a ser contrastado con nuestro actual estado de conocimientos sobre la «época de las Reformas», un tiempo que transcurre entre el primer tercio del siglo XVı y mitad del siglo XVII y en el que, bajo el telón de fondo de las Reformas protestante y católica, Europa se vio sacudida por una serie de guerras que la historiografía tradicional calificó de «guerras de religión», reconceptualizadas ahora de manera pertinente y más ajustada a la realidad como conflictos confesionales.

* Esta investigación ha sido posible gracias a la ayuda concedida al proyecto «Políticas cainitas: la visión política desde la teoría mimética» por el Instituto de Investigaciones Económicas y Sociales de la Universidad Francisco de Vitoria el 28 de febrero de 2018. 
Creemos que Rene Girard podría estar en lo cierto si, por una parte, comprobamos que las guerras de religión se intensificaron no en los primeros tiempos de la Reforma protestante, sino en los años posteriores, cuando pareció estar consolidada. Y por otra parte, si el fervor religioso, efectivamente, declinó hasta el punto de no ser la religión el motivo fundamental de esas guerras. Así pues, el objetivo de estas páginas es el de verificar estos planteamientos y, desde la perspectiva girardiana, tratar de reinterpretar tales acontecimientos.

Al mismo tiempo, abriendo otra línea de investigación y de acuerdo con los planteamientos de rivalidad mimética y del mecanismo de los chivos expiatorios, en otro texto, René Girard señaló como chivo expiatorio de esa violencia religiosa al Sacro Imperio Romano Germánico (Girard, 2010, p. 178).

Lo más llamativo de la afirmación con la que hemos comenzado es que iba en contra de la idea ampliamente difundida y compartida en medios académicos y entre el gran público de que precisamente con la Reforma protestante se intensificó el fervor religioso hasta tal punto que condujo a esa serie de guerras que asolaron Europa durante buena parte de los siglos XVI y XVII. Además, como señala W. Cavanaugh, esta idea ya estaba presente en algunos escritos de teoría política del siglo XVII (Cavanaugh, 2010, p. 235 y ss.).

Desde nuestro punto de vista, en sintonía con la idea de Girard, lo que ocurrió en realidad fue que el fervor religioso fue sustituido por el fervor «confesional» con la consecuente carga política que esto suponía de aumento de la presencia del naciente «Estado moderno» (Ruiz Rodríguez y Sosa Mayor, 2007).

En realidad, la rivalidad entre la Iglesia católica y las iglesias reformadas no era por su diferenciación en lo más nuclear de la religión cristiana (la salvación por la fe), sino por otros temas menos esenciales. Como afirmaba Charles Taylor a propósito de esta rivalidad: «Si la salvación por la fe hubiera sido lo más importante, la coexistencia podría haber sido concebible» (Taylor, 2014, p. 132).

Por tanto, resulta más que dudosa la afirmación de que solo gracias al nacimiento y fortalecimiento del Estado moderno secularizado se lograría poner fin a las sangrientas guerras de religión. En realidad, el conflicto nacería del surgimiento de los nuevos Estados, que tratarían de afirmarse desde principios confesionales diferenciados que al sustituir las viejas identidades medievales por nuevas identidades reforzaban sus nacientes formas políticas.

Así pues, la paradoja desvelada por Girard de que la verdadera causa de las guerras de religión no fue el aumento de la identidad religiosa sino, quizás, su disminución resulta más verosímil de lo que inicialmente se podía pensar. ¿Qué evidencias o, al menos, qué indicios podemos encontrar para confirmar la tesis girardiana? Para intentar dar respuesta a estas preguntas debemos adentrarnos en el análisis histórico de esa etapa de la historia europea cotejándolo con la teoría del conflicto mimético tal y como lo planteaba Girard y asumiéndolo como clave interpretativa de esos conflictos confesionales (las mal llamadas guerras de religión) en la Europa de los siglos xvı y xvII.

Cronológicamente, estos conflictos comenzaron en la década de 1520, no mucho después del inicio de la ruptura luterana, y finalizaron en 1648 con la paz de Westfalia. Un hito importante, aunque no definitivo, fue la llamada paz de Augsburgo, que en 1555 temporalmente puso fin a las guerras entre el Imperio y la alianza de los príncipes protestantes, la llamada Liga de Esmalcalda. El principal acuerdo fue que los gobernantes seculares determinarían la 
religión de sus súbditos, bien católica, bien luterana, excluyendo las demás confesiones. En el caso de las ciudades imperiales libres donde existieran ambos grupos, luteranos y católicos, para los dos se mantendría la libertad de culto. Por último, en el caso de los territorios dependientes de un gobernante eclesiástico, la religión sería la católica y si el prelado abrazara alguna confesión reformada debería dimitir para ser sustituido por un prelado católico. Pero en los años siguientes, los conflictos entre gobernantes y gobernados se multiplicarían hasta desembocar en una guerra abierta.

Nuestro análisis comienza con una aproximación a un concepto clave y controvertido pero importante para entender las relaciones de dependencia. Nos referimos al concepto de identidad individual. La identidad individual puede ser entendida como la percepción o sentimiento que tiene el individuo sobre sí mismo y en relación con los demás. Frente a esta identidad también hay otra que es la colectiva o de grupo. La identidad colectiva surge cuando los individuos de un grupo se ven a sí mismos como similares y distintos de otros por lo que generan una definición colectiva interna (Mercado, 2010, p. 235). Por tanto, el concepto de identidad nos hace reflexionar sobre la idea del hombre como ser individual y ser social a la vez. Esta realidad genera una tensión que se percibe en el estudio de la historia. Todos queremos ser individuales y, por tanto, necesitamos defender un espacio de libertad, pero al mismo tiempo nuestra dimensión colectiva nos obliga invariablemente a recurrir al amparo de la colectividad que nos limita y disciplina. El resultado es que nos vemos obligados a crear relaciones de dependencia.

Vinculado a la identidad colectiva está la presencia del Estado, que no es más que una forma de ordenar el poder que genera dependencias. El Estado surge como necesidad ante la incapacidad del hombre para resolver los diversos problemas que de forma natural aparecen cuando actúa individualmente, e incluso cuando se muestra con carácter familiar.

De esta forma vemos cómo la dimensión social del ser humano no es una mera suma de individualidades, sino que hay también elementos objetivos que se establecen por medio de relaciones de poder, relaciones de dependencia que aseguran la vida social.

Por tanto, las identidades son construcciones y deconstrucciones que hace el propio hombre. $Y$ esto es lo que claramente se manifiesta en el periodo al que nos estamos refiriendo y más concretamente a lo largo del siglo xVI y buena parte del xVII. Es en este momento histórico cuando se desarrollan nuevas formas de organización sociopolítica a consecuencia de la desestructuración de la sociedad política y, en general, de la cristiandad latina que había tenido lugar en los siglos anteriores. Es lo que la historiografía conoce como la crisis de la Baja Edad Media.

En esta crisis se plantea una nueva cosmovisión del mundo que es la que llega con el humanismo y el renacimiento. $Y$ de la mano de este movimiento se trata de recuperar el papel del hombre como protagonista de la historia. Una nueva identidad que buscaba equilibrar el exceso del teocentrismo que se desarrolló a lo largo de la Edad Media con un empuje al antropocentrismo. A consecuencia de esto se recupera la idea de forjar un hombre nuevo como elemento básico de la sociedad, lo que necesariamente venía unido a la idea de Reforma. Todo había de ser reformado, todo llevaba a un proceso de reformas que acabó en ruptura de la unidad de la cristiandad latina.

Lo que vino después, a consecuencia de aquella ruptura, fueron dos propuestas de reforma enfrentadas, cada una con su propia visión del hombre, del mundo y de la relación 
entre los hombres y con Dios: la que fue desarrollando la Reforma protestante y la que defendió la reforma católica.

Durante no poco tiempo ha predominado una visión historiográfica que planteaba la idea de que la Reforma protestante había provocado su antítesis en la Contrarreforma católica y que a través de esa rivalidad se podría explicar el absolutismo como forma de resolver ese conflicto. Esta visión, de resonancia marxiana, que ha tenido mucha fortuna historiográfica, hoy en día se ha puesto en tela de juicio, aunque todavía se sigue repitiendo como una cantinela (Po-Chia Hsia, 2010, p. 18 y ss.). En realidad, la Reforma católica se inició mucho antes de las propuestas de Lutero y partía del corazón de la propia cristiandad. Como señala Lutz: «Ya antes de la aparición de Lutero y de Zwinglio se había activado un proceso de reestructuración profunda de la tradicional simbiosis cristiano-secular, que había caracterizado a lo largo de muchos siglos la cultura y sociedad europeas» (Lutz, 2008, p. 36).

Como es bien conocido, en los años finales de la Edad Media se hizo necesario una revisión profunda de la experiencia cristiana ante el hundimiento de la cosmovisión medieval. Y fruto de esa revisión, surgieron muchas corrientes reformadoras, especialmente a partir del siglo xIv y del siglo xv; por ejemplo, la devotio moderna y otras formas de espiritualidad profunda, sentida e intimista, que hacían valer, como elemento cultural importante, la libertad de conciencia. En principio, esta importancia de la libertad de conciencia encajaba muy bien con el papel del nuevo hombre. El problema vino cuando las posiciones radicales de Lutero llevaron este principio a darle una primacía absoluta frente a la autoridad. Como es sabido, él hizo prevaler su libertad de conciencia y búsqueda de la salvación individual frente a la autoridad y la colectividad. Se rompía así un posible equilibrio entre los dos polos que dieran armonía al conjunto sociocultural que fue lo que acabó después de numerosos intentos de conciliación y concordias en ruptura.

Por otra parte, la Iglesia siempre se ha movido en el principio de autoridad. Naturalmente, alguien tiene que definir lo que es canónico y lo que no es canónico; alguien dotado de autoridad para ello. Esa autoridad se opone a ciertas formas de libertad con el fin de mantener una unidad frente a la disgregación a la que pueden conducir quienes solo se guían por lo que tan solo les dicta su conciencia. Por tanto, surge así una tensión entre los dos polos de libertad y autoridad, que es lo que subyace en el núcleo de ese proceso reformador.

El resultado de tan fuerte tensión fue la ruptura de la unidad eclesial y por tanto de la unidad cultural dentro de la cristiandad latina en virtud de la libertad de conciencia que Lutero llevó hasta las últimas consecuencias. Para el agustino, uno de los factores que más pesaron sobre él fue la de su propia salvación. Se aferraba a la idea que se tenía del hombre como una dualidad de «cuerpo y alma», aunque lo único que permaneciera fuese el alma. Por tanto, para Lutero la salvación de cualquier persona dependía más de la fidelidad a su espíritu o a lo que le dictase su propia conciencia que a lo que proclamase la autoridad.

De este modo, como es sabido, esta visión se saldó con una ruptura con planteamientos dicotómicos no solo desde un punto de vista teológico, sino que trascendió a los ámbitos de la cultura y de la política. Concretamente, en el ámbito de lo político, para muchos príncipes, apelando a estos principios de libertad, que iban asociados a la individualidad, se hacían fuertes en su oposición a cualquier autoridad por encima de ello, fuera la del Papa o la del Emperador o la de ambos, para lograr así una independencia de estos supremos poderes que hasta entonces habían sido los verdaderos poderes soberanos. 
En otras palabras, muchos poderes políticos se dieron cuenta de que por medio de la libertad de conciencia y contraponiendo su libertad frente a la autoridad podían cuestionar la jerarquía política a la que están subordinados. Surgía así una ruptura con la fuente de soberanía que hasta entonces había operado y se daba paso a una constelación de nuevos soberanismos políticos que enseguida fundamentaron nuevas entidades políticas con sus propias soberanías (que es lo que conceptualiza Bodino a finales del siglo xvl). Tenemos aquí el origen del protonacionalismo europeo, que acabaría en el alumbramiento de lo que históricamente se conoce como Estados nacionales.

Fue de esta manera como los poderes de muchos príncipes del Sacro Imperio abandonaron los fundamentos de su legitimidad política vinculados con el Emperador y el Papa y se convirtieron en poderes independientes, con los consiguientes conflictos, que ensangrentaron la cristiandad durante casi siglo y medio. Por tanto, de la ruptura de la unidad cultural de la cristiandad latina y del proyecto primigenio universalista se pasó a una individualidad particularizada en diferencias políticas que acabarían con el surgimiento de nuevo poderes, que de forma gradual fueron cada vez más soberanos, hasta desembocar en lo que hoy conocemos como Europa de las naciones.

Pero, por otra parte, y ante tanta diversidad, también se puso en juego otra rivalidad. Fue la lucha por la hegemonía en aquel entorno político entre la casa de Austria (los Habsburgo) y la monarquía francesa (Lutz, 2008, p. 48). Se reforzaba así el factor político mediante la pugna entre Estados, lo que dio lugar a múltiples alianzas que trascendían el ámbito de lo religioso, incluso de lo confesional, para dar de manera creciente la primacía a lo político. La paz de Westfalia marcaría los primeros compases hacia el fin de los conflictos confesionales y el triunfo de las individualidades políticas, así como la sanción legal de principios como el de la tolerancia religiosa. Este es el origen de la secularización de la cultura que desembocará en la Europa de las naciones, aunque los Estados nacionales propiamente dichos no aparecieran hasta finales del siglo XVIII y principios del xIX (Ruiz Rodríguez y López González, 2012).

Debemos subrayar que antes de la aparición los Estados nacionales lo que se produjo fue un proceso de construcción política de unos Estados que eran de matriz fuertemente confesional. Es decir, que estaban definidos y buscaban una identidad a partir de un elemento cultural y religioso. Una identidad o una identificación que, naturalmente, conformaba una unidad de criterio interna que permitía configurar un sujeto, tanto político como cultural.

Por tanto, aquella crisis en la unidad cultural y religiosa con sus fuertes lazos de pertenencia dejó paso a múltiples confesiones. El origen de este concepto es el de la palabra latina confesio, término historicista que hace referencia a la pertenencia a un credo y unas iglesias que se hace explícitamente obligatoria (Ruiz Rodríguez, 2007). La Iglesia, la Ecclesia, no era una comunidad obligatoria, era voluntaria. A partir del momento en que irrumpe la confesionalización, la pertenencia a una Iglesia deja de ser una elección personal. Ya no hay una sola Iglesia católica, hay diversas iglesias. La iglesia calvinista, la iglesia luterana, la iglesia católica, todas rivalizando entre sí (Gregory, 2015, p. 131). Desde ese momento empiezan a formarse comunidades a cuya pertenencia están obligados los súbditos no en virtud de su libre elección sino en virtud de la decisión de su príncipe. Fue el principio emanado de la paz de Augsburgo en 1555, acuñado como Cuius regio, eius religió, por el que se aceptaba que la religión de los súbditos debería ser la misma que la de sus príncipes. En aquel cambio político no se podía admitir que el sujeto político gobernable fuera leal a su señor si se debía a algún 
credo superior. Es decir, la lealtad se definía por la confesión y no se podía exigir lealtad sin unidad confesional.

Por lo tanto, la idea de confesionalización nos parece que es clave a la hora de entender estas nuevas identidades; es un elemento que se refuerza y corre paralelo al levantamiento de estos nuevos Estados modernos y que luego se traslada a la construcción del Estado nacional. La identidad nacional se constituye como cimiento de nuevos estados, estados que evidentemente en un proceso largo, pasado por la llustración, llegan a constituirse como entes sacralizados que sustituyen el principio de soberanía divina por el principio de soberanía nacional. Ya no es Dios quien delega el poder en el gobernante, sino la nación. La cohesión interna que hace funcionar a las sociedades modernas bajo el liderazgo de los príncipes se ha conseguido gracias a la unanimidad confesional.

El Estado es el único capaz de resolver lo que necesita el ciudadano sacralizando la política porque se ha convertido en un estado sacralizado. Eso lo sintetiza muy bien el nacionalismo. El nacionalismo como doctrina política identitaria nace en el siglo XIX, muy vinculado con la tradición ilustrada. Precisamente en un movimiento de reflujo y de vuelta atrás, vuelven a emerger hoy en día los nacionalismos en un momento en que la globalización pone en cuestión muchas identidades inventadas y que generan incertidumbres; y por tanto, cuanta más globalización más localismo. Según Girard:

Todas las sociedades humanas sin excepción tienen tendencia a descomponerse bajo el efecto de su violencia interna. Cuando esta se produce, disponen de un medio de restablecimiento que se les escapa a ellas mismas y que la antropología no ha descubierto jamás, la convergencia espontánea, mimética de toda la comunidad contra una víctima única, el "chivo expiatorio» original, sobre el que todos los odios se descargan sin expandirse catastróficamente por su entorno, sin destruir la comunidad. (Girard, 2006, p. 46).

Contrastado este planteamiento con la época de la ruptura protestante y las guerras de religión que le siguieron podemos encontrar una rivalidad de naturaleza religiosa en la sociedad cristiana, «la cristiandad». En este caso, la violencia interna tiene su origen en el deseo de atraer para sí por parte de cada una de las iglesias al mayor número posible de fieles. Tanto las iglesias reformadas como la Iglesia católica compiten entre sí por convertir o mantener en su propia fe a toda la cristiandad o, al menos, la mayor parte posible. En esta rivalidad toman partido las más altas autoridades políticas, tanto católicas como protestantes. La rivalidad religiosa se amplía, de este modo, a rivalidad política.

Pero el objeto de deseo, la comunidad de fieles que forma la cristiandad no se puede compartir en tanto que los fieles no pueden optar por una y otra fe a la vez. Deben elegir. Tampoco es fácil llegar a un acuerdo o reparto. Tanto católicos como protestantes definen sus ortodoxias y sus heterodoxias, lo que conduce a la diferenciación y definición de unos y otros y, por tanto, a la abominación del adversario: la gran babilonia o los perros herejes. Para los poderes políticos, los heterodoxos, es decir, los que no comparten la misma confesión, son los disidentes peligrosos a los que hay que perseguir y extirpar si no se retractan de sus creencias. 
Para completar el panorama, los poderes políticos eran demasiado numerosos. El Sacro Imperio, epicentro de los conflictos confesionales, con una población a principios del siglo XVII de unos 20 millones de habitantes, estaba fragmentado en unas 1.000 unidades políticas diferentes y con diversos grados de autonomía (Parker, 2003, p. 19).

Este sería el fundamento de aquel periodo de guerras que hemos definido como confesionales y que asolarán Europa durante buena parte del siglo XVı y hasta la mitad del siglo XVII.

En este sentido, tal y como algunos historiadores lo han expresado (Parker, 2001, p. 222), no era lo mismo la conformidad o vivencia externa del creyente de la fe que proclamaba su príncipe, a la que se veía obligado a adherirse, y la conversión, o adhesión sincera de la propia conciencia a la fe que se le predicaba.

Los líderes religiosos católicos y protestantes eran conscientes de esa realidad, pero pocos se conformaban con la mera vivencia externa. Pretendían llegar a la conversión. Por tanto, unos y otros utilizaron todas las vías posibles para llegar a esa conversión interna, en general con resultados bastante desalentadores (Parker, 2001, p. 221 y ss.).

La mayor parte de la población no tenía ningún problema en aceptar formalmente la fe de su príncipe. Cuando era católico se hacía católica y cuando era protestante se convertía en protestante. La facilidad en el cambio de confesión era una clara señal de que lo que había era una conformidad externa, lo que en definitiva mostraba una clara debilidad de los lazos de dependencia. Los lazos religiosos como urdimbre de la sociedad occidental se habían comenzado a aflojar en una dinámica imparable.

Por esta razón, a la vez que se clarificaban los principios dogmáticos de cada iglesia, desde la Confesión de Augsburgo de 1530 hasta la Profesión de fe tridentina de 1564, se profesionalizaba y se institucionalizaba la educación en la fe por medio de la formación de los clérigos y del personal de cada iglesia, así como en la instauración de diversas instituciones y mecanismos para el control y la disciplina (Schilling, p. 19).

Así pues, unos y otros movilizaron todos sus recursos para contrarrestar esta tendencia secularizadora. El catolicismo, por su parte, no tuvo ningún problema en establecer, digámoslo así, diferentes discursos. Discursos para las élites y discursos para el pueblo. Lo que había que hacer era saber adaptarse, saber identificarse con las perspectivas de cada uno de esos interlocutores. Los protestantes intentaron otras vías más intelectuales. En todo caso, esta rivalidad mimética no trajo ningún vencedor, claro. Por eso no es de extrañar que la única solución que lograra abrirse paso para poner fin a esa espiral destructiva fuera la de la tolerancia religiosa. Si los lazos de dependencia cada vez eran menos consistentes, por qué no ser más tolerantes con los que manifestaban otro credo, si, a fin de cuentas, podían ser tan buenos súbditos (tan dependientes políticamente con respecto al Estado) como los practicantes de la confesión mayoritaria. De esta manera, si, por una parte, se abrían nuevos espacios para la tolerancia religiosa en el plano de las conciencias individuales, por otra, en el plano institucional, se reforzaba el control político de los Estados confesionales sobre sus iglesias.

Por tanto, la tolerancia religiosa no fue ningún principio, sino el resultado de una realidad, el resultado de una praxis. Los primeros en avanzar en este campo fueron los holandeses. Inicialmente, en los primeros años de la recién estrenada independencia persiguieron el catolicismo. Pero al cabo de un tiempo permitieron practicar su religión a los que querían mantenerse en la fe católica. Su identidad religiosa no era ninguna amenaza para su sistema político. Se movía en otro plano de la realidad social. 
Esa tolerancia a la vez que debilitaba las identidades las realineaba. El orden político medieval había sido un orden jerárquico y sacralizado. En el vértice de esa res publica christiana se encontraban el Papa y el Emperador. Pero la Reforma protestante había trastocado ese orden y generado un conflicto religioso y político. La violencia había ido creciendo en una escalada incapaz de detenerse. La tolerancia y el respeto al statu quo se asumió; esto solo fue posible porque se logró al final encontrar un chivo expiatorio. Este chivo expiatorio fueron los poderes universales, las autoridades supremas del orden político medieval. Papado e Imperio, acusados de un modo u otro de ser origen de la violencia religiosa, desempeñarían el papel de chivos expiatorios. Por eso, la paz de Westfalia, punto final de las guerras de religión, más allá de ratificar un statu quo entre católicos y protestantes supuso la retirada del papado como agente de la realidad política y, por tanto, la secularización de la política. Pero también supuso la retirada del Imperio como forma política integradora del mundo cristiano.

Papado e Imperio fueron pues desterrados, como chivos expiatorios, de la dirección de la ciudad política. Como hemos comentado anteriormente, René Girard supo ver ese papel de chivo expiatorio que asumió el Imperio. En un párrafo de su libro Clausewitz en los extremos comenta lo siguiente:

La intervención estadounidense, al término de la Segunda Guerra, era sin duda el último acto del drama napoleónico, que formó un todo con el drama de la Europa misma, librada desde hace siglos a sus crecientes odios miméticos. Es muy sintomático, bajo ese aspecto, que sea el Sacro Imperio Romano Germánico el que haya cumplido el rol de chivo expiatorio durante más de tres siglos: ello implicaba la única posibilidad política de Europa, y en torno y en contra de esa reliquia carolingia que los europeos se mataron unos a otros. (Girard, 2010, p. 178).

Sin embargo, René Girard, que había señalado a la Iglesia católica y al cristianismo en general como chivos expiatorios del mundo actual (Girard, 2006, p. 87 y ss.) no supo ver que en este caso también el papado fue víctima propiciatoria del nuevo orden político que se estaba configurando.

A partir de la paz de Westfalia el Emperador pasó a ser un soberano más en un entorno donde todos los Estados más poderosos competirían por obtener la supremacía en Europa. Lo mismo le ocurrió al Papa; su soberanía temporal se redujo a los Estados Pontificios. En cuanto a su soberanía espiritual, el Sumo Pontífice tuvo que rivalizar con las nuevas soberanías de las iglesias reformadas. Solo le quedó reconocida una autoridad espiritual sobre los católicos, no exenta de cuestionamientos, como fue el caso del regalismo. Las nuevas fidelidades a partir de entonces se reconocerían fundamentalmente en torno al poder político, en torno a los Estados nacionales.

Si la paz de Westfalia supuso el fin definitivo de la idea de cristiandad como núcleo de la identidad de los europeos, habría que pensar que por otra parte supuso un límite a la dinámica autodestructiva que había comenzado un siglo antes. Quizás, gracias a ello, Europa se libró de caer en manos del Imperio otomano, gran beneficiario de las rivalidades entre los europeos. Como ya señalaba en uno de sus sermones santo Tomás de Villanueva: 
Y en la Iglesia latina (el diablo) tampoco deja de sembrar cizaña, sino que, como veis, ha sembrado herejías en Alemania, y una guerra atrocísima e interminable entre España y Francia. El daño que ha hecho a la Iglesia esta discordia es conocido por todos, habiéndose perdido Belgrado, y Budapest, y una gran parte de Hungría, y la isla de Rodas, que era la puerta de la cristiandad. En conclusión, ¿de dónde vino el aumento del poderío turco, cómo alcanzó tanta importancia su imperio sino por las desavenencias de los cristianos? (Villanueva, 2012, p. 413).

No muchos años después de firmarse la paz de Westfalia, en el año 1683, los turcos volvieron a asediar Viena, la capital del Imperio, pero esta vez las fuerzas unidas de todo el Sacro Imperio, más la ayuda de los polacos, lograron derrotar a los invasores.

Por otra parte, la rivalidad entre Francia y España se decantó en favor de la primera. A partir de entonces el peso político de la monarquía española fue disminuyendo gradualmente en Europa. Como contrapartida, podríamos decir que España se volcó en sus territorios ultramarinos, forjando una cultura común a ambos lados del Atlántico, la cultura hispánica.

Pero, ciertamente, las rivalidades internas entre los poderes europeos no desaparecieron. La confesionalización y las monarquías absolutas supusieron el traspaso de la soberanía desde los poderes universales a los nuevos poderes nacionales secularizados. El Estado moderno fue desplegándose de una manera imparable. A las viejas rivalidades le sucedería una nueva rivalidad entre Estados que lejos de disminuir fue in crescendo.

\section{Bibliografía}

Cavanaugh, W. T. (2010). El mito de la violencia religiosa. Ideología secular y raíces del conflicto moderno. Granada: Nuevo Inicio.

Girard, R. (2006). Aquel por el que llega el escándalo. Madrid: Caparrós Editores.

— (2016). «Belongings». Contagion: Journal of Violence, Mimesis, and Culture (23), pp. 1-12.

- (2010). Clausewitz en los extremos. Política, Guerra y Religión. Barcelona: Katz.

Gregory, B. (2015). The Unintended Reformation. How a Religious Revolution Secularized Society. Cambridge: Belknap Press.

Lutz, H. (2008). Reforma y contrarreforma. Europa entre 1520 y 1648. Madrid: Alianza.

Mercado Maldonado, A. y Hernández Oliva, A. V. (2010). «El proceso de construcción de la identidad colectiva». Convergencia. Revista de Ciencias Sociales (53), pp. 229-251.

Parker, G. (2001). El éxito nunca es definitivo. Imperialismo, guerra y fe en la Europa moderna. Madrid: Taurus.

- (2003). La Guerra de los Treinta Años. Madrid: A. Machado Libros.

Po-Chia Hsia, R. (2010). El mundo de la renovación católica, 1540-1770. Madrid: Ediciones Akal.

Ruiz Rodríguez, J. I. y López González, C. (2012). «El Sacro Imperio. Política, religión y protonacionalismo en el mundo germánico», Identidades confesionales y construcciones nacionales en Europa (ss. XV-XIX). Madrid: Universidad de Alcalá. 
Ruiz Rodríguez, J. I. (2007). «El concepto de confesionalización en el marco de la historiografía germana». Studia Historica. Historia Moderna (29), pp. 279-305.

Schilling, H. (2008). Early Modern European Civilization and its Political and Cultural Dynamism. Lebanon: University Press of New England.

Taylor, Ch. (2014). La era secular. Tomo I. Barcelona: Gedisa.

Villanueva, T. de (2012). Obras completas. Vol. IV. Madrid: Biblioteca de Autores Cristianos. 